\title{
Primary Acquired Melanosis: Clinical, Histopathologic and Optical Coherence Tomographic Correlation
}

\author{
Yahya A. Alzahrani ${ }^{a}$ Smita Kumar ${ }^{a}$ Hassan Abdul Aziz ${ }^{a}$ Thomas Plesec ${ }^{b}$ \\ Arun D. Singh ${ }^{a}$ \\ a Department of Ophthalmic Oncology, Cole Eye Institute, and ${ }^{\mathrm{b}}$ Anatomic Pathology, Cleveland Clinic, Cleveland, \\ Ohio, USA
}

\section{Key Words}

Corneal epithelium · Correlative microscopy .

Immobilization stress - Melanoma - Noninvasive diagnostic tool $\cdot$ Optical coherence tomography

\begin{abstract}
Aim: To assess the use of anterior segment optical coherence tomography (OCT) as an adjuvant diagnostic tool in primary acquired melanosis (PAM) by correlating clinical, histopathologic and anterior segment OCT findings. Methods: Twenty-four patients (24 eyes) with PAM of the conjunctiva, cornea or both were imaged with an anterior segment OCT device (RTVue, model-RT100; Optovue Inc., Fremont, Calif., USA). Results: Histopathologic diagnosis following excisional or incisional biopsy was confirmed in 13 out of 24 patients (54.6\%). OCT images showed a characteristic uniformly thick basal epithelial hyperreflective band (about $20 \mu \mathrm{m}$ thick) and normal thickness of the overlying epithelial layer in all patients (100\%). The hyperreflective band on OCT correlated with the basal epithelial melanocytic pigmentation noted on histopathologic examination but did not vary in thickness between cases with or without atypia. Conclusions: The characteristic basal epithelial hyperreflective band with normal overlying epithelium in the absence of cysts observed in
\end{abstract}

all cases by anterior segment OCT correlated with clinical and histopathologic features of conjunctival and corneal PAM. Anterior segment OCT may be helpful as a noninvasive diagnostic tool for PAM. Improvement in resolution is necessary to detect melanocytic hyperplasia and aytpia suggestive of malignant potential.

(c) 2015 S. Karger AG, Basel

\section{Introduction}

Conjunctival primary acquired melanosis (PAM) is an acquired flat, painless noncystic pigmented lesion of the conjunctiva $[1,2]$. PAM usually occurs unilaterally in middle-aged individuals (mostly Caucasians) and accounts for $11 \%$ of all conjunctival tumors and for $21 \%$ of all conjunctival melanocytic lesions [2]. It can either be regarded as benign (PAM without atypia) or as a precancerous lesion (PAM with atypia) [3-7]. More recently, the spectrum of histopathologic features within PAM has been emphasized rather than an absolute distinction between PAM without or with atypia [8]. Histopathologically, PAM without atypia is best characterized by melanocytic hyperpigmentation along the basal epithelial layer of the conjunctiva, while atypia refers to melanocytic

\section{KARGER}

E-Mail karger@karger.com

www.karger.com/oop
(C) 2015 S. Karger AG, Basel

2296-4681/15/0023-0123\$39.50/0
Arun D. Singh, MD

Department of Ophthalmic Oncology Cole Eye Institute, Cleveland Clinic

2022 E 105th St, Cleveland, OH 44106 (USA)

E-Mail singha@ccf.org 
hyperplasia comprised of isolated or confluent nests of atypical melanocytes $[3,5,7]$.

Anterior segment OCT is a relatively new diagnostic tool that is being investigated for various anterior segment disorders [9]. Spectral domain OCT offers higher resolution of approximately $5 \mu \mathrm{m}$ compared to time domain OCT, with a resolution of 10-18 $\mu \mathrm{m}$ [10-13]. Spectral domain OCT has been investigated as adjunct in the management of ocular surface lesions for diagnosis, treatment planning and monitoring of response $[9$, 14-16].

As conjunctival or corneal PAM may be subtle and difficult to document on clinical examination and by conventional photography, we have investigated the role of a commercially available spectral domain anterior segment OCT device in detecting PAM by investigating the correlation of clinical, histopathologic and OCT findings.

\section{Patients and Methods}

This case series included 24 eyes of 24 consecutive patients with a clinical diagnosis of conjunctival or corneal PAM. All patients underwent complete ophthalmic examination. After the initial clinical diagnosis was made, slit lamp examination and anterior segment OCT imaging were performed with a commercially available device (RTVue, model-RT100; Optovue Inc., Fremont, Calif., USA), with a resolution of $5 \mu \mathrm{m}[26,000 \mathrm{~A}$-scan(s)] and using a wavelength of $840 \mathrm{~nm}$. Horizontal or vertical scans of the lesions were acquired. Thirteen patients out of 24 underwent excisional or incisional biopsy to confirm the diagnosis.

\section{Results}

Twenty-four eyes of 24 patients with a clinical diagnosis of conjunctival/corneal PAM were included in this study. There was a female predominance ( 15 females vs. 9 males). The mean age was 64 years (range 31-94). Clinical findings included a patch of flat, ill-defined pigmented epithelial lesions noticed on slit lamp examination (100\%; fig. 1a, 2a). Nineteen patients (79.6\%) had only conjunctival involvement, while in 4 patients (16.6\%), the pigmentation was extend across the limbus into the adjacent cornea (fig. 3), and 1 patient (4.16\%) had isolated corneal PAM. Conjunctival cysts were absent in all patients (100\%). Eleven patients (45\%) were observed without biopsy or chemotherapy because the lesion was small, stable over follow-up, or the patient was asymptomatic.

Histopathologic specimens of 13 patients (55\%) who underwent excisional or incisional biopsy were studied.
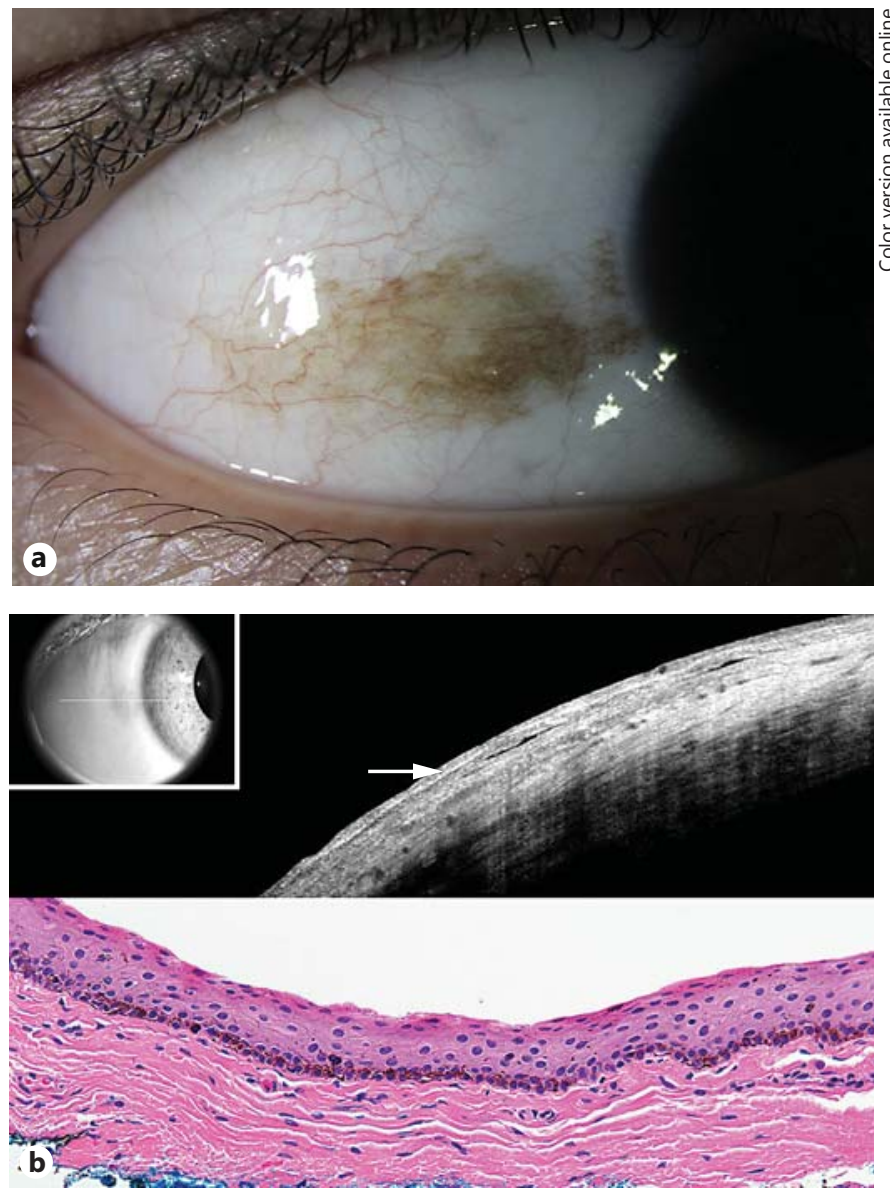

Fig. 1. a Localized conjunctival PAM without atypia. b Note the basal epithelial hyperreflective band of approximately $20 \mu \mathrm{m}$ thickness (arrow, above) and the corresponding melanocytic hyperpigmentation that is restricted to the basal layer (below). HE. $\times 200$.

The specimens showed melanocytic hyperpigmentation within the basal layer of the epithelium in all cases (fig. 1b, $2 b)$. Nine out of 13 patients (69\%) additionally showed melanocytic hyperplasia which is compatible with the diagnosis of PAM with atypia (fig. 4b), characterized by cytological (nuclear enlargement, prominent nucleoli and abundant cytoplasm) and architectural atypia (melanocytic extension of the basal layer and nesting of cytologically atypical melanocytes), while 4 patients (31\%) showed only melanocytic hyperpigmentation without cytologic or architectural atypia, indicative of PAM without atypia (fig. 1b, 2b). Stromal extension or invasive melanoma and conjunctival cysts were absent in all histopathologic samples $(100 \%)$.

Anterior segment OCT demonstrated a uniformly thick basal epithelial hyperreflective band in all cases 

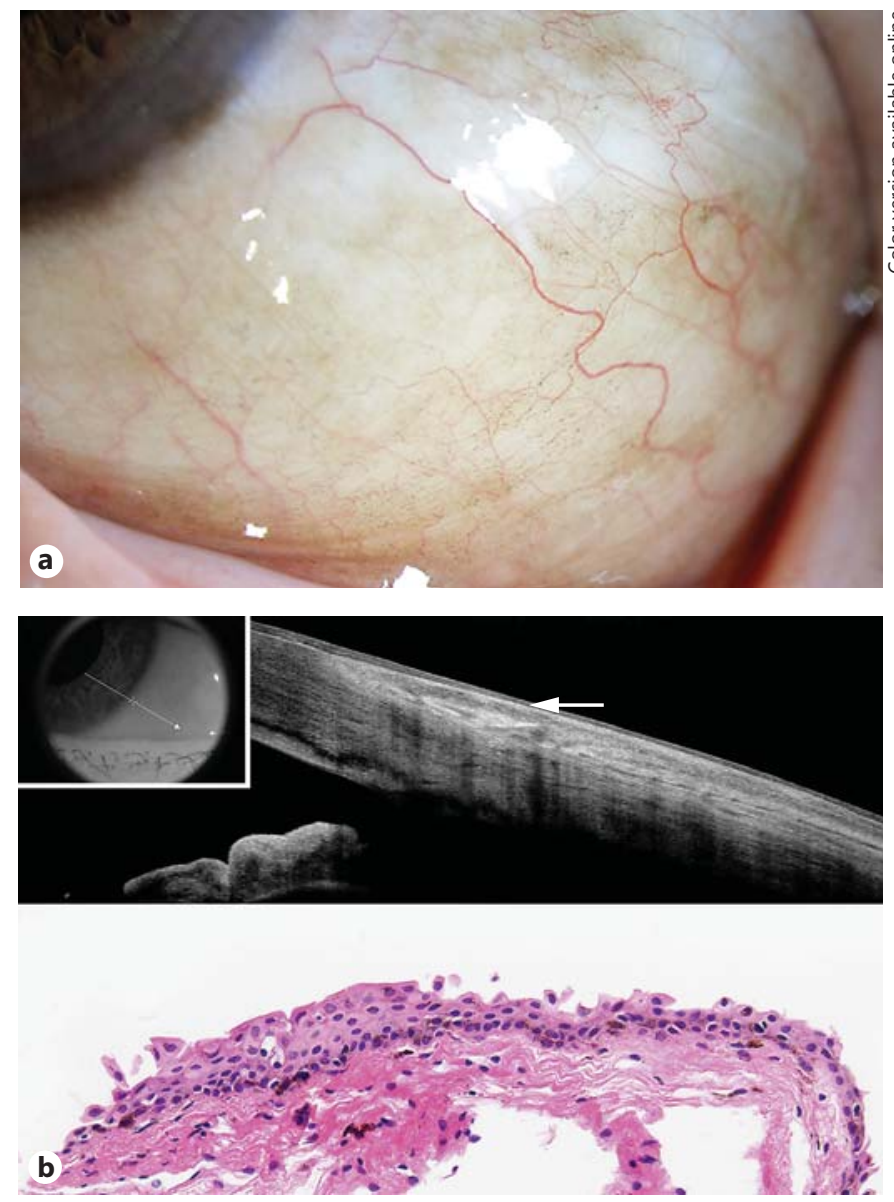

Fig. 2. a Diffuse conjunctival PAM without atypia. b Note the basal epithelial hyperreflective band of approximately $20 \mu \mathrm{m}$ thickness (arrow, above) and the corresponding melanocytic hyperpigmentation that is restricted to the basal layer (below). HE. $\times 200$.

(100\%; fig. 2b, 3, 4b). The overlying epithelium was normal in all patients (100\%). Optical shadowing (partial or total) of subepithelial layers was observed in 6 patients (25\%). Conjunctival cysts were absent in all patients (100\%).

The histopathology of examined specimens showed a high correlation with the OCT findings. Cases of PAM sine pigmento were not observed in this series. The melanocytic hyperpigmentation within the basal layer of the epithelium correlated with the hyperreflective band observed on anterior segment OCT (fig. 1b, 2b). Also, normal overlying epithelium and the absence of conjunctival cysts, observed on clinical and histopathologic evaluation, correlated with the OCT findings (100\%). Optical shadowing noted on OCT correlated with the amount of melanocytic pigmentation observed on the histopatho-

PAM: Clinical, Pathologic and OCT Correlation

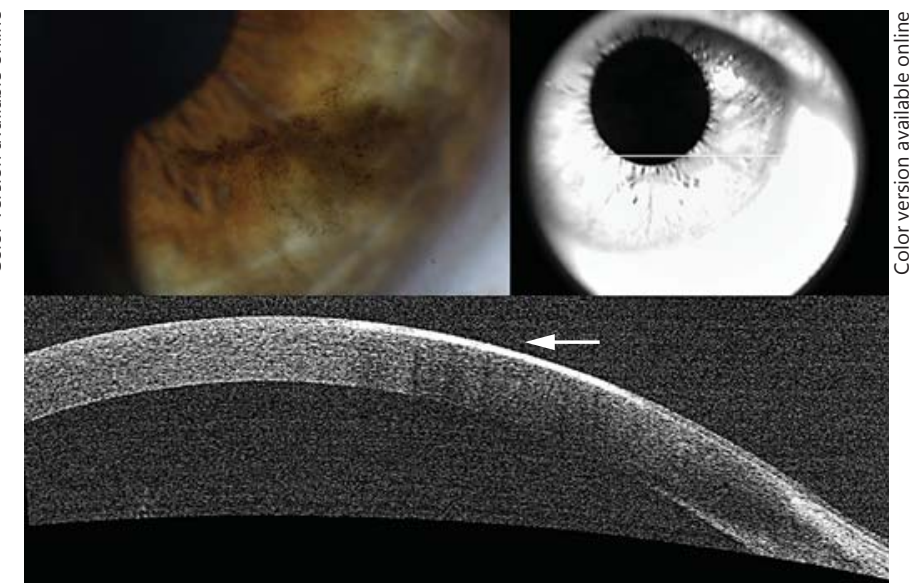

Fig. 3. Corneal PAM. a Clinical appearance. b Note the corresponding epithelial hyperreflective band (arrow).
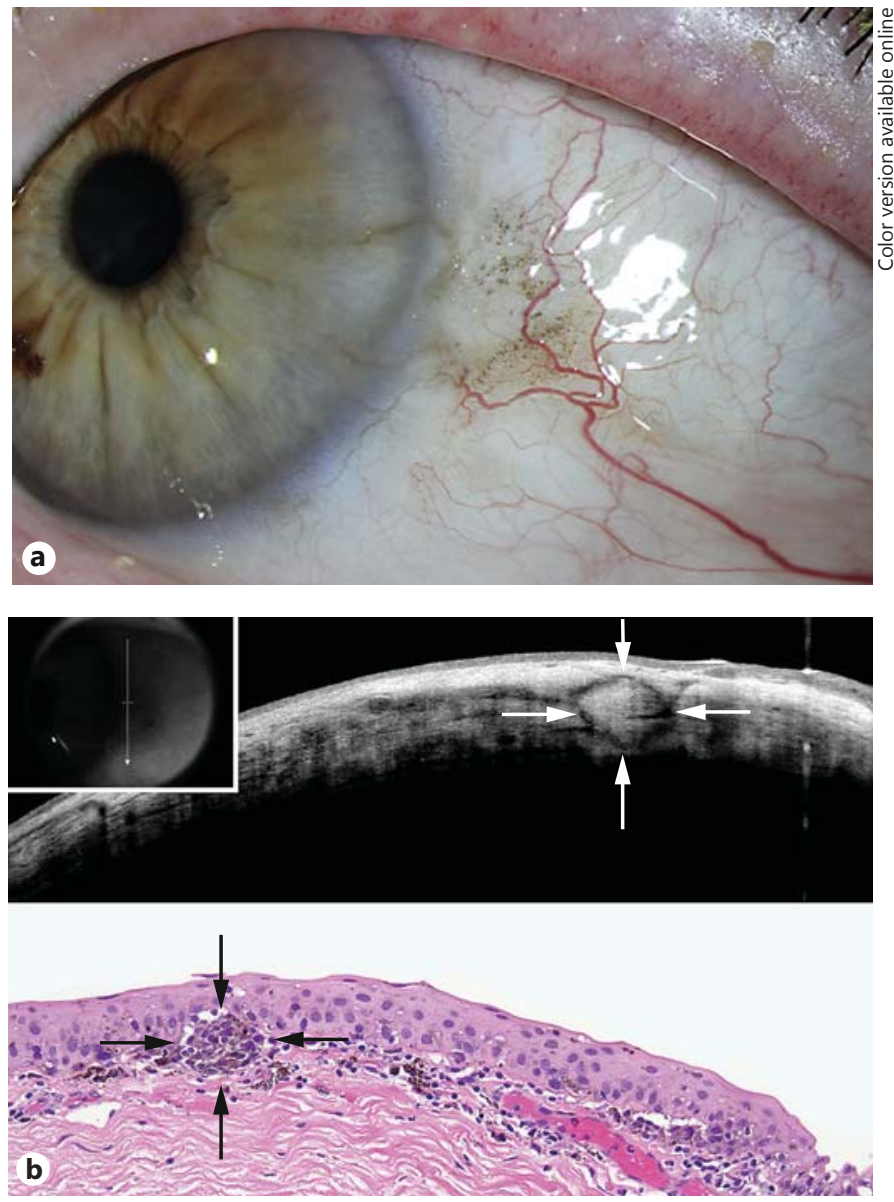

Fig. 4. a Localized conjunctival and corneal PAM with atypia. b Note the round stromal hyperreflective zone (arrows, above) with similar appearance of an atypical melanocytic nest (arrows, below). HE. $\times 200$. Without point-to-point correlation between the OCT and the histopathologic image, no definite correlation can be derived. 
Table 1. Conjunctival melanocytic lesions: comparison of typical anterior segment OCT features

\begin{tabular}{lllll}
\hline Diagnosis & $\begin{array}{l}\text { Epithelial } \\
\text { hyperreflective } \\
\text { band }\end{array}$ & Stroma & $\begin{array}{l}\text { Shad- } \\
\text { owing }\end{array}$ & Cyst \\
\hline PAM & +++ & normal & $+/-$ & absent \\
Nevus & ++ & $\begin{array}{l}\text { normal/abnornal } \\
\text { abnormal }\end{array}$ & ++ & present \\
Melanoma & + & & ++ & absent \\
\hline
\end{tabular}

logic sample. It was not possible to differentiate cases of PAM with atypia from those without atypia by OCT as the hyperreflective band did not vary in thickness between the cases with or without atypia. However, in 1 case with melanoma in situ (PAM with atypia), an atypical melanocytic nest observed on histopathology showed a similar appearance on OCT (fig. 4b).

\section{Discussion}

Anterior segment OCT imaging technology provides a noninvasive adjunct diagnostic tool to the gold standard histopathology specimen in ocular surface lesions such as ocular surface squamous neoplasia [14-18]. Limited studies have investigated other conjunctival lesions such as nevi and melanoma $[17,18]$. We have analyzed the correlation of clinical, histopathologic and OCT findings of conjunctival and corneal PAM using a commercially available spectral domain anterior segment OCT device.

The characteristic features of PAM (with or without atypia) observed in our series include a uniform basal hyperreflective band of approximately $20 \mu \mathrm{m}$ thickness (100\%) with normal overlying epithelium and absence of cysts in all cases (100\%). Our observations are similar to those reported by Abou Shousha et al. [14] and Nanji et al. [18] who reported an epithelium of normal thickness and a regular hyperreflectivity of the basal epithelium with the use of ultra-high- and high-resolution OCT in 8 and 8 cases, respectively $[14,18]$. Cases of PAM sine pigmento were not observed in this series. In such rare cases, there would be no hyperreflective band on OCT, with or without epithelial thickening.

In contrast to PAM, conjunctival nevi characteristically have a high likelihood of conjunctival cysts (77$100 \%)$ [17] with normal epithelium [17, 18]. Both PAM and nevi have an epithelial layer of normal thickness on OCT $[14,18]$. In contrast, conjunctival melanoma ap- pears as a hyperreflective, thickened epithelium with extension of hyperreflectivity into the subepithelial layer and significant optical shadowing which may obscure the underlying tissue $[14,18]$. Characteristically, cysts are absent in melanoma on OCT [18]. Comparative OCT findings of conjunctival and corneal melanocytic lesions are summarized in table 1.

Optical shadowing is a major limitation of anterior segment OCT. The identification of the posterior extent of the lesion can be obscured by optical shadowing, which is directly influenced by the extent of melanocytic pigmentation and the thickness of the lesion, and hence, limits the use of OCT for full characterization of the nevus or melanoma, as they tend to thicken. The corneal epithelium [17] PAM, which tends to be flat by clinical criteria, is less susceptible to this limitation, as observed in this study. An additional limitation of the anterior segment OCT device used in this study was its inability to differentiate cases of PAM with atypia from those without atypia, as the hyperreflective band did not vary in thickness between the cases with and those without atypia. Meticulous studies with point-to-point correlation between the OCT and histopathologic images are required before any definite conclusions regarding the ability of OCT to detect histopathologic atypia can be reached (fig. 4). Nevertheless, anterior segment OCT is an excellent tool for imaging the anterior surface and lateral extent of the lesions.

In summary, the characteristic basal epithelial hyperreflective band with a normal overlying epithelium in the absence of cysts observed in all cases by anterior segment OCT correlated with clinical and histopathologic features of conjunctival and corneal PAM. Anterior segment OCT may be helpful as a noninvasive diagnostic tool for PAM. Improvement in resolution is necessary to detect intraepithelial melanocytic hyperplasia (atypia) suggestive of malignant potential.

\section{Statement of Ethics}

The study protocol has been approved by the Institute's Committee on Human Research. The study application was approved as Exempt Research by the Institutional Review Board for the collection of data in an anonymous manner in which participants were not identifiable.

\section{Disclosure Statement}

The authors declare no conflicts of interest. 


\section{References}

1 Gloor P, Alexandrakis G: Clinical characterization of primary acquired melanosis. Invest Ophthalmol Vis Sci 1995;36:1721-1729.

2 Shields JA, Shields CL, Mashayekhi A, et al: Primary acquired melanosis of the conjunctiva: experience with 311 eyes. Trans Am Ophthalmol Soc 2007;105:61-72.

3 Folberg R, Jakobiec FA, Bernardino VB, Iwamoto T: Benign conjunctival melanocytic lesions. Clinicopathologic features. Ophthalmology 1989;96:436-461.

4 Griffith WR, Green WR, Weinstein GW: Conjunctival malignant melanoma originating in acquired melanosis sine pigmento. Am J Ophthalmol 1971;72:595-599.

5 Folberg R, McLean IW, Zimmerman LE: Primary acquired melanosis of the conjunctiva. Hum Pathol 1985;16:129-135.

6 Folberg R, McLean IW: Primary acquired melanosis and melanoma of the conjunctiva: terminology, classification, and biologic behavior. Hum Pathol 1986;17:652-654.
7 Grossniklaus HE, Green WR, Luckenbach M, Chan CC: Conjunctival lesions in adults. A clinical and histopathologic review. Cornea 1987;6:78-116.

8 Damato B, Coupland SE: Conjunctival melanoma and melanosis: a reappraisal of terminology, classification and staging. Clin Experiment Ophthalmol 2008;36:786-795.

9 Medina CA, Plesec T, Singh AD: Optical coherence tomography imaging of ocular and periocular tumours. Br J Ophthalmol 2014; 98:1140-1146.

10 Ackerman AB, Sood R, Koenig M: Primary acquired melanosis of the conjunctiva is melanoma in situ. Mod Pathol 1991;4:253-263.

11 Wang M, Luo R, Liu Y: Optical coherence tomography and its application in ophthalmology. Yan Ke Xue Bao 1998;14:116-120.

12 Jancevski M, Foster CS: Anterior segment optical coherence tomography. Semin Ophthalmol 2010;25:317-323.

13 Radhakrishnan S, Rollins AM, Roth JE, et al: Real-time optical coherence tomography of the anterior segment at $1310 \mathrm{~nm}$. Arch Ophthalmol 2001;119:1179-1185.
14 Shousha MA, Karp CL, Canto AP, et al: Diagnosis of ocular surface lesions using ultrahigh-resolution optical coherence tomography. Ophthalmology 2013;120:883-891.

15 Kieval JZ, Karp CL, Abou Shousha M, et al: Ultra-high resolution optical coherence tomography for differentiation of ocular surface squamous neoplasia and pterygia. Ophthalmology 2012;119:481-486.

16 Shousha MA, Karp CL, Perez VL, et al: Diagnosis and management of conjunctival and corneal intraepithelial neoplasia using ultra high-resolution optical coherence tomography. Ophthalmology 2011;118:1531-1537.

17 Shields CL, Belinsky I, Romanelli-Gobbi M, et al: Anterior segment optical coherence tomography of conjunctival nevus. Ophthalmology 2011;118:915-919.

18 Nanji AA, Sayyad FE, Galor A, Dubovy S, Karp CL: High-resolution optical coherence tomography as an adjunctive tool in the diagnosis of corneal and conjunctival pathology. Ocul Surf 2015;13:226-235. 